\title{
Trabalho e subjetividade: o olhar da Psicodinâmica do Trabalho
}

\author{
Selma Lancman ${ }^{1}$ e Seiji Uchida ${ }^{2}$
}

\begin{abstract}
O presente artigo discute alguns aspectos teóricos da relação entre subjetividade e organização do trabalho. Para tanto, nos pautamos nos principais alicerces teóricos da abordagem dejouriana: a psicanálise, a hermenêutica e a teoria da ação. Buscamos subsidiar o leitor que queira se utilizar da clínica do trabalho em suas ações de intervenção e pesquisa a avançar teoricamente e a se familiarizar com o debate atual desenvolvido pela Psicodinâmica do Trabalho.
\end{abstract}

Palavras-chave: Saúde Mental e Trabalho, Subjetividade, Psicodinâmica do Trabalho.

$\mathrm{T}$ emos como objetivo discutir a importância da subjetividade hoje e o modo como apreendê-la nas organizações do trabalho a partir de uma abordagem atualmente conhecida como Psicodinâmica do Trabalho. Isso significa privilegiar uma determinada ótica, ou seja, aquela que articula sofrimento e saúde no trabalho.

Antes de tratarmos da questão propriamente dita, gostaríamos de contextualizar o problema sobre o qual estamos nos propondo a refletir.

Taylor (1995), quando propôs a Organização Científica do Trabalho (OCT) e sua tripla divisão (divisão do modo operatório, divisão entre órgãos de concepção intelectual e execução e divisão dos homens), aparentemente buscou eliminar a subjetividade do trabalho por meio do controle dos corpos dos trabalhadores cindidos de suas mentes.

$\mathrm{Na}$ realidade, ao observarmos sua concepção de organização como um todo, ele reafirma a importância da subjetividade. A direção e os planejadores - para produzir e impor as diretrizes da empresa, sua política, sua estratégia e seus objetivos - necessitam pensar, decidir, planejar, avaliar, assim por diante. Dejours e Abdoucheli (1994) afirmam que numa organização hierarquizada do tipo piramidal quanto mais se sobe na estrutura da empresa, mais se abrem as possibilidades para a expressão e imposição dos desejos de quem ocupa os postos de chefia. Nesse sentido, somente a alta direção poderia manifestar mais plenamente os seus anseios, pensamentos e desejos. A subjetividade dos trabalhadores é reafirmada pela necessidade de seu controle para que aquilo que foi traçado seja rigorosamente cumprido. Dito de outro modo, sua importância é reconhecida pelo avesso, ou seja, para evitar ao máximo a possibilidade dos trabalhadores criarem obstáculos e desvios na produção. Logo, quanto mais se desce na hierarquia da empresa, menor vai ser a possibilidade de expressão de seus pensamentos e desejos na condução das atividades.

Desde então a subjetividade dos trabalhadores é vista, no mínimo, com desconfiança enquanto a dos dirigentes é valorizada. Logo, não se trata na realidade de perguntar se a subjetividade é fundamental ou não hoje, uma vez que ela está sempre presente, mas qual é o lugar que ocupa e que importância tem no contexto atual.

\footnotetext{
${ }^{1}$ Professora do Departamento de Fisioterapia, Fonoaudiologia e Terapia Ocupacional da Faculdade de Medicina Universidade de São Paulo.

${ }^{2}$ Professor da Escola de Administração de Empresa de São Paulo, Fundação Getúlio Vargas.
} 
Por exemplo, desde que a ergonomia francesa, na década de 80 , fez a distinção entre o trabalho prescrito e o trabalho real, o modo como os trabalhadores lidam com a distância entre eles passa a ser uma questão essencial a ser tratada. Dejours desenvolve os conceitos de inteligência prática e sabedoria prática para dar conta dessa "face oculta do trabalho" (Dejours, 1993b, p. 47). Falar em inteligência e saber prático vai muito além do saber-fazer prático, dos conhecimentos informais e de experiências vividas. $\mathrm{O}$ que os diferencia é que a inteligência e a sabedoria prática se enraízam no corpo, é desde a vivência corporal do trabalho que estas vão sendo gestadas. Implicam também uma prática ardilosa, um modo astucioso de lidar com os problemas e enigmas do trabalho. Finalmente, são utilizadas em todas as tarefas e atividades para compreender aquilo que resiste às prescrições e saberes atuais e para engendrar estratégias criativas, inovadoras e engenhosas.

Com a crise dos anos 70, Harvey defende a tese de que vivemos um momento de transição do fordismo-keynnesiano (hegemonia do capital industrial) para o da acumulação flexível do capital:

[a acumulação flexível do capital] é marcada por um confronto direto com a rigidez do fordismo (...) se apóia na flexibilidade dos processos de trabalho, dos mercados de trabalho, dos produtos e padrões de consumo. Caracteriza-se pelo surgimento de setores de produção inteiramente novos, novas maneiras de fornecimento de serviços financeiros, novos mercados e, sobretudo, taxas altamente intensificadas de inovação comercial, tecnológica e organizacional. A acumulação flexível envolve rápidas mudanças dos padrões do desenvolvimento desigual, tanto entre setores como entre regiões geográficas, criando, por exemplo, um vasto movimento no emprego no chamado "setor de serviços", bem como conjuntos industriais completamente novos (...) (Harvey, 2000, p. 140).

É importante assinalar também que a flexibilização da produção implica, ao mesmo tempo, a necessidade de flexibilização do mercado consumidor. No dizer de Harvey (2000), seguindo a escola da regulação ${ }^{3}$, trata-se de transformar as formas de reprodução, ou seja, todas as relações sociais que sustentam e re-põem as relações de produção, para que a nova lógica de acumulação do capital possa se tornar hegemônica4 .

Especialistas em economia política e história econômica discutem se essas mudanças significam uma nova forma de acumulação (Harvey, 2000) ou se são apenas uma repetição de ciclos históricos do capitalismo (Arrighi, 2000). Não nos deteremos nessa polêmica, pois para os objetivos deste trabalho, uma outra discussão parece-nos essencial: o novo contexto organizacional traz a flexibilização ou a precarização do trabalho?.

Para nós essa discussão é fundamental, pois está diretamente relacionada ao lugar que a subjetividade ocupa atualmente. É consenso entre muitos autores (Bergamini, 1994, 1997; Motta \& Caldas, 1997; Freitas, 2000; Kets de Vrie, 1997) que trabalham com as questões organizacionais que temas como motivação, liderança, trabalho em equipe, talentos, gestão de pessoas, cultura organizacional, clima organizacional, gestão participativa etc., são fundamentais hoje para que as empresas possam não só sobreviver, mas, se possível, vencer a dura batalha da competição.

\footnotetext{
${ }^{3}$ A Escola da Regulação propõe tratar com abrangência e profundidade teórica os processos de transformação da economia sob a ótica da acumulação de capital, empregando categorias e conceitos que transcendem o aparato habitual da análise econômica, em direção aos elementos que conferem coesão social, em particular ao papel do Estado (Possas, 1988, p. 195).

${ }^{4}$ No sentido definido por Gramsci (Cf. Rouanet, 1978).

${ }^{5}$ Vide Dejours (1999a).
} 
Autores como Womack, Jones e Roos (1992), Wagner III e Hollenbeck (1999), Boyett e Boyett (1999) defendem que a flexibilização do trabalho surge como uma necessidade imposta pela nova ordem econômica e que põe novos desafios à questão da subjetividade. Em geral, eles vêem a flexibilização como um fenômeno positivo e defendem que não se deve mais tentar controlar nem amordaçar a subjetividade como foi a intenção taylorista. Hoje, criatividade, iniciativa própria, sensibilidade, maturidade pessoal, capacidade de interação interpessoal, liderança, devem ser pesquisadas, compreendidas e desenvolvidas. Para se ter vantagens competitivas e agregação de valores deve-se valorizar esse novo perfil psicológico.

Os anos 80 e 90 foram pródigos em experiências que demonstraram a importância cada vez maior das pessoas. Velhas conquistas sindicais tornaram-se obsoletas e novas demandas surgiram: não só novas leis e novas relações entre Capital e Trabalho, mas também novas formas de subjetividade. O desmoronamento do estável mundo fordistakeynnesiano tornou necessário o surgimento de um sujeito que fosse criativo, inovador, flexível, adaptável, resiliente etc.

Ora, ao observarmos algumas das principais teorias psicológicas ${ }^{6}$ que foram utilizadas para dar suporte teórico para os managers preocupados em formar esse novo homem, constatamos que eles estão mais preocupados com os processos e os mecanismos psíquicos que explicam um determinado comportamento e sua mudança do que com os sujeitos da ação.

Destoando dos defensores dessa nova ordem, Dejours (1999a) e Sennett (1999) escrevem textos contundentes e críticos em relação às novas formas organizacionais. Sennet fala que a instabilidade criada pela nova lógica de acumulação do capital - chamada por ele de capital "impaciente" - vem corroendo o caráter das pessoas.

Dejours, de seu lado, afirma que assistimos a um processo de precarização do trabalho. O autor compara a situação atual em que as empresas se encontram a uma nova Guerra Mundial com todas as conseqüências de tal fato. A competição hoje, diferentemente daquela dos tempos pré-anos 80 , tem como principal característica a destruição do competidor, seja pela lógica da fusão, seja por uma política que leva à eliminação e quebra das concorrentes.

Temos consciência de que a realidade é mais complexa e diversificada. Essa descrição somente esboça tendências que ocorrem no mundo dito globalizado, ou seja, naqueles países que estão num processo de integração da produção e do consumo, dos meios de comunicação e dos meios de transportes.

Falar da precarização do trabalho implica ter presente esse horizonte para podermos entender a realidade subjetiva vivida pelos trabalhadores, ou seja, de conviver em um mundo onde se perdeu uma série de garantias trabalhistas, direitos adquiridos, conquistas que protegiam não só socialmente, mas psiquicamente as pessoas.

Dejours fala, por exemplo, da banalização da injustiça social - inspirado em Hannah Arendt (2000), que criou o conceito de banalização do mal. Com o desemprego estrutural criado pela nova forma de acumulação, tanto os que têm emprego como aqueles que o perderam, sofrem intensamente. A ameaça da demissão ronda a cabeça daqueles que permaneceram empregados. Muitos gestores passam a utilizar-se dessa possibilidade como técnica de administração de pessoas, criando uma pressão freqüentemente insuportável. Passam a fazer exigências absurdas e irrealizáveis. O problema é que todos, inclusive os trabalhadores, acreditam que podem e tentam cumprir as demandas. Os subordinados, cinicamente chamados de colaboradores, ao se verem nessa situação, irão inevitavelmente sofrer patogenicamente.

${ }^{6}$ Vide, por exemplo: a) a teoria da hierarquia das necessidades de Maslow (1954) e b) a da dissonância cognitiva de Festinger (1975). 
Um outro dado que deve ser considerado é a questão ética: a maioria das pessoas (chefias e funcionários), nessas novas condições, é forçada a agir contra seus princípios morais. Cria-se então um intenso sofrimento. A saída para todos tem sido a banalização da injustiça social. $\mathrm{O}$ mal passa a ser visto como algo necessário, mais que necessário, como algo que deve fazer parte do cenário organizacional. Há uma naturalização da prática social injusta, vivenciada pelas pessoas como mal dos tempos modernos, imutável, como causalidade do destino, causalidade econômica ou sistêmica (Dejours 1999a). Nesse sentido, o processo de re-produção do capital acaba produzindo essa nova forma de ser social: corroído em seu caráter (Sennett, 1999), banalizado pelo mal.

Mas, apesar dessa dura crítica, em seu trabalho com relação às instituições e organizações, Dejours caminha na direção oposta do seu ceticismo. No seu dia-a-dia como pesquisador e psicodinamista produz conceitos, teorias e metodologias que criam esperanças de que a realidade possa ser diferente, ou seja, modificada.

Passaremos a discorrer sobre algumas questões que perpassam a obra do autor. Hoje já existe uma considerável obra produzida tanto por Dejours como por seus seguidores. Nosso objetivo, insistimos, não é o de fazer uma apresentação exaustiva da Psicodinâmica do Trabalho, mas tão somente tecer considerações que permitam a sua compreensão em geral.

Em seu percurso teórico, o autor coloca-se inicialmente dentro de uma tradição francesa conhecida como Psicopatologia do Trabalho, inaugurada pelos psiquiatras sociais Sivadon, Guillant e Begoin (Billiard, 2001). Essa escola, a exemplo das teorias formuladas pela medicina ocupacional, buscava o nexo causal entre determinadas organizações e condições de trabalho e o adoecimento mental. Dejours, assim como outros autores influenciados por essas idéias, tinha como escopo compreender o sofrimento psíquico no trabalho e todo o seu esforço era dirigido então no sentido de estabelecer relações entre as injunções e constrangimentos organizacionais e a desestabilização psicológica dos indivíduos. Esperava-se que dadas certas condições ambientais, as pessoas iriam necessariamente descompensar psiquicamente.

Mas Dejours, partindo do trabalho de campo e estudando situações concretas de trabalho, observava que freqüentemente isso não ocorria, o que o deixava um tanto perplexo. Ao contrário, encontrava o que denominou "um estranho silêncio". Não encontrava os "ruídos" da loucura do trabalho, mas um estado de normalidade.

Nesse ponto, o autor percebe a emergência de um novo foco de pesquisa e seu olhar se desloca para esse novo fenômeno. A questão agora passa a ser a enigmática normalidade produzida pelos indivíduos. Aquilo que é natural e óbvio para as pessoas passa a ser um problema a ser explicado. Dada a ampliação do objeto de pesquisa, Dejours passa a chamar o seu novo campo de pesquisa e as teorias que passa a formular de Psicodinâmica do Trabalho (Dejours, 1993a).

No nosso entender, o que o autor defende a partir desse momento é que não se deve confundir estado de normalidade com estado saudável. Se, de um lado, a normalidade pode refletir equilíbrio saudável entre as pessoas, pode, de outro, ser um sintoma de um estado patológico, ou seja, o estabelecimento de um precário equilíbrio entre as forças desestabilizadoras dos sujeitos e o esforço destes e dos grupos no sentido de se manterem produtivos e atuantes à custa de muito sofrimento e que se estenderá também em sua vida fora do trabalho.

Esse sofrimento não se manifesta porque os sujeitos buscam ativamente se proteger e defender. Lançam mão ou de mecanismos de defesa, quando trabalham sós e isolados, ou de estratégias de defesa, quando o trabalho é em equipes e grupos. A patologia surge quando se rompe o equilíbrio e o sofrimento não é mais contornável. Em outros termos, quando um 
certo trabalhador utilizou todos os seus recursos intelectuais e psico-afetivos para dar conta da atividade e demandas impostas pela organização e percebe que nada pode fazer para se adaptar e/ou transformar o trabalho.

Para que possamos entender todas essas afirmações mais profundamente e não ficarmos na superfície de suas considerações é essencial que saibamos que o autor desenvolve seus conceitos tendo como uma de suas interlocutoras, um dos pilares teóricos, a Psicanálise?

Ela permite uma compreensão nova da realidade organizacional. Para ficarmos somente em um exemplo, a Psicanálise adverte os pesquisadores da psicologia clínica que o comportamento psicopatológico (fruto de formações do inconsciente) é sobredeterminado, ou seja, sua compreensão "remete para uma pluralidade de fatores determinantes". Da mesma forma que uma palavra não pode ser reduzida a um sinal, pois pode encerrar múltiplos sentidos, o comportamento deve ser visto como sintoma, constituído de deslizes e de sobreposições de sentido.

A forma como Dejours entende estado de normalidade, então, só é de fato compreensível quando temos em mente que esse fenômeno é constituído de múltiplas determinações subjetivas e objetivas. E o que torna esse conceito ainda mais complexo é que não se trata de um fenômeno somente individual, como no caso da Psicanálise, mas, ao mesmo tempo, de um fenômeno coletivo e que está articulado ao mundo do trabalho.

Isso significa lembrarmos que, como bem adverte Ferreira no Prefácio às Conferências Brasileiras (1999b), Dejours fala de três racionalidades do trabalho:

Ao lado da racionalidade em relação à produção, a mais conhecida, e que tem como critério a eficácia, existem também a racionalidade em relação ao mundo social, a normas e valores de convivência no trabalho, e finalmente uma racionalidade em relação à saúde mental e física, ao mundo subjetivo de cada um (p. 9).

Ora, quando falamos da normalidade enquanto resultado de um compromisso entre o sofrimento e as estratégias de defesa, isso significa que no trabalho a normalidade supõe sempre a existência do sofrimento. Como diz Dejours (1999b), a normalidade é uma conquista "mediante uma luta feroz entre as exigências do trabalho e a ameaça de desestabilização psíquica e somática" (p. 19). A racionalidade em relação à saúde mental e física passa, então, sempre pela experiência vivenciada do sofrimento.

A questão agora é se perguntar pela lógica dessa racionalidade pessoal. Dejours afirma que o sofrimento é, antes de tudo, um sofrimento do corpo: "não pode haver sofrimento sem carne" (1999b, p. 19). O sofrimento é também individual, da ordem do singular. Mas, como bem vimos, essa racionalidade deve ser compreendida em sua relação com as outras duas racionalidades. Todo o problema situa-se então nessa difícil articulação lógica entre elas.

\footnotetext{
${ }^{7}$ A Psicodinâmica do Trabalho vem se desenvolvendo e estabelecendo um debate contínuo com pesquisadores e cientistas de outras áreas: ergonomistas, filósofos, sociólogos do trabalho, psicólogos clínico e do trabalho, lingüistas, psicanalistas etc.

${ }^{8}$ Para Laplanche e Pontalis (1976), em seu Vocabulário da Psicanálise, essa definição de sobredeterminação pode ser tomado em dois sentidos bastantes diferentes: “a) A formação considerada é resultante de diversas causas, pois que uma só não basta para a explicar; b) A formação remete para elementos inconscientes múltiplos, que podem organizar-se em seqüências significativas diferentes, cada uma das quais, a um certo nível de interpretação, possui sua coerência própria. Este segundo sentido é o mais admitido" (p. 641).
} 


\section{Sofrimento psíquico e trabalho}

Aqui, a Psicanálise nos ajuda a compreender como a Psicodinâmica do Trabalho pensa e apreende essa vivência no trabalho. Vai ser por meio do conceito psicanalítico de angústia que Dejours irá pensar a gênese do sofrimento que pré-existe ao trabalho\%. Buscará analisar como ela se origina no sujeito em suas relações primitivas com os pais. A criança, inicialmente, é susceptível à angústia dos pais, principalmente aquela com a qual os pais têm dificuldades de lidar. Ao vivenciá-la passa a senti-la como se fosse sua, pois nesse momento de sua vida não tem condições de distinguir o que é seu e o que é dos seus pais. Quando adquire a capacidade de falar, tenta expressar essa angústia para poder elaborá-la, mas infelizmente não encontra espaço psíquico propício nos pais, pois estes não têm condições de ajudá-la na medida em que a criança recoloca em cena aquilo que os fez sofrer. Essa angústia não elaborada vai adquirir uma característica enigmática e será origem de uma curiosidade jamais satisfeita, de um desejo de saber e compreender que periodicamente será reposto pelas situações conjunturais, ou seja, estas funcionariam como fatores desencadeantes da primitiva curiosidade. Ao mesmo tempo, irá constituir-se como zona de fragilidade psíquica do sujeito, uma face obscura e para sempre desconhecida. Um dos espaços sociais privilegiados em que a criança, ao se tornar adulto, vai repor essa angústia é o trabalho. Nesse locus procurará, indiretamente, elaborar esse sofrimento primitivo e, a cada enigma do trabalho que resolver, sentirá que se fortalece psiquicamente e a zona de obscuridade diminuirá um pouco. Dejours chamará de ressonância simbólica a esaa complexa relação entre o mundo psíquico e o mundo do trabalho.

Para a apreensão das angústias vividas no trabalho, Dejours, inspirado na Psicanálise, propõe uma atividade de escuta atenta à fala dos trabalhadores. Não só a fala individual, mas principalmente a coletiva ${ }^{10}$. Isso porque, para a Psicodinâmica do Trabalho, se o sofrimento é da ordem do singular, sua solução é coletiva. Para tanto é fundamental que se crie o que o autor chama de espaço público, espaço de circulação da palavra coletiva. É na escuta do que é expresso que se cria a possibilidade do sofrimento emergir e sua solução ser pensada por todos.

Como bem demonstrou a Psicanálise, fala e escuta autênticas não são dissociáveis. São atividades intrinsecamente ligadas e uma não existe sem a outra. A construção do espaço público pelo coletivo do trabalho passa necessariamente pela aprendizagem da escuta e da fala. É um processo complexo, cheio de conflitos, discussões, confrontos, deliberações e arbitragens entre as diversas pessoas. $O$ futuro dessa construção é incerto e desconhecido. No plano pessoal, exige-se muito dos indivíduos engajados nesse processo. Freqüentemente os efeitos são desastrosos para os trabalhadores quando não ocorre o reconhecimento. Para que haja então um comprometimento pessoal mais duradouro nesse processo, é necessário que eles vejam a possibilidade de retribuição para os seus esforços:

\footnotetext{
“(...) a forma específica da retribuição é o reconhecimento no sentido duplo do termo: reconhecimento no sentido de admitir essa contribuição da pessoa e reconhecimento no sentido de gratidão" (Dejours, 1999b, p. 29, itálicos do autor).
}

\footnotetext{
${ }^{9} \mathrm{O}$ autor vai desenvolver uma das possíveis gêneses da angústia. Isso não significa que estamos defendendo aqui que essa seja a única possibilidade, mas tão somente que se trata da posição de Dejours.

${ }^{10}$ Dejours (1999b) tem uma posição muito clara sobre o coletivo do trabalho: "O essencial para a saúde mental individual, nas relações com o trabalho, é a ação sobre o funcionamento do coletivo. O coletivo não é apenas um grupo. $\mathrm{O}$ que o define é a construção comum de regras e ofícios (...) é muito difícil construir um coletivo". Em outra passagem o autor vai chamar de atividade deôntica, a atividade de construir acordos, normas e valores que se estabilizam sob a forma de regras.
} 
Não se trata de qualquer reconhecimento, mas sim do reconhecimento dos pares, na medida em que estes conhecem a fundo o trabalho e podem avaliá-lo em aspectos por vezes menos visíveis para os leigos. O autor tem consciência de que o julgamento dos pares é o mais severo e crítico. Ao passar pelo escrutínio deles e receber sua aprovação, o trabalhador sente-se retribuído e sai fortalecido desse processo. Junto a esse reconhecimento, um outro é citado por Dejours: o de utilidade, aquele feito pelo cliente e pela chefia. Esses dois mecanismos de reconhecimento são fundamentais, pois o que em última instância está em jogo é sua identidade. Ela se constitui no interjogo das relações sociais, sendo que um dos elementos essenciais para sua produção é o reconhecimento social. $O$ trabalho, nesse sentido, é um campo privilegiado na conquista da identidade pelos indivíduos.

Cabe aqui uma consideração sobre o reconhecimento social no campo do trabalho: ele ocorre de forma indireta em relação à atividade. Nesse sentido, "o que o sujeito procura fazer reconhecido é o seu fazer e não o seu ser (...) Somente depois de ter reconhecida a qualidade do meu trabalho é que posso, em um momento posterior, repatriar esse reconhecimento para o registro da identidade" (Dejours, 1999b, p. 21). Desse modo sintético podemos compreender como Dejours articula as três racionalidades apontadas por Ferreira.

\section{O sentido do trabalho}

Gostaríamos de apontar agora uma outra questão que perpassa a discussão realizada até o presente momento e que é essencial na discussão sobre trabalho e subjetividade. Tratase da questão da produção da significação, do sentido do trabalho pelos indivíduos. Isso implica, para o pesquisador, a difícil tarefa de aceder ao sentido das condutas e comportamentos dos sujeitos no trabalho, compartilhar a significação que estes atribuem às suas ações.

Como a Psicodinâmica do Trabalho situa-se nas trilhas abertas da tradição compreensiva nas Ciências Humanas, isso significa defender a concepção de um sujeito "responsável pelos seus atos e capaz de pensar, de interpretar os sentido da situação em que se encontra, de deliberar ou de decidir e de agir". Significa supor que ele possui inteligência isso em dois sentidos: "inteligência como competência cognitiva e inteligência como liberdade de aceder à inteligibilidade, à compreensão das coisas ou da situação (inteligência das coisas)". É admitir que ele (o trabalhador) “...age em função da razão” (Dejours, 1999c, p. 207).

Compreender as racionalidades das ações de um sujeito com essas características significa pôr a difícil questão da interpretação com todas as conseqüências possíveis: "seu estatuto, sua verdade, sua validação, sua verificação" (Dejours, 1999c, p. 207). Não nos parece à toa que Dejours será conduzido diretamente a discutir a questão da hermenêutica. Dois serão os seus interlocutores: Gadamer e Ricoeur.

Gadamer é importante pois seu projeto consiste não em desenvolver "um processo de compreensão, mas elucidar as condições que permitem a compreensão" (Dejours, 1999c, p. 208). Em outras palavras, Gadamer renuncia a fazer da hermenêutica o fundamento das ciências humanas: "a tarefa da hermenêutica é a de elucidar o milagre da compreensão, não da comunhão misteriosa das almas, mas a da participação de uma significação comum" (p. 208). As condições que tornam o projeto hermenêutico possível são: reabilitação dos pressupostos; reabilitação da autoridade da tradição; o sentido de um texto ultrapassa seu autor; interpretação, compreensão do sentido, distância crítica e acesso ao horizonte do outro; 
recolocação; o problema da aplicação; o problema da relação com a ética; e compreender é re-apreender a questão do outro" ${ }^{11}$.

Vai ser Ricoeur quem vai repor a questão dos fundamentos para a hermenêutica recusada por Gadamer. Segundo Dejours, Ricoeur propõe um meio de ultrapassar a oposição clássica entre ciências da natureza e ciências do espírito, entre explicar e compreender, e retoma o problema da arbitrariedade da interpretação, ressaltando também a da validação. Logo, o interesse em dialogar com Ricouer decorre do fato desse autor distinguir e discutir três operações essenciais no processo de interpretação: a validação, a objetivação e a avaliação.

Conclui que do ponto de vista epistemológico, Ricoeur e Gadamer chegam a um forte consenso entre eles: o antipsicologismo. Que as ciências da natureza e as positivistas excluam a subjetividade de suas atividades científicas enquanto condição básica da objetividade é compreensível, mas isso ocorrer com a hermenêutica deixa Dejours perplexo. Com efeito, diz Ricouer, sintetizando a posição de ambos: "É necessário afirmar firmemente que a questão que se trata de reconstituir diz respeito em primeiro lugar, não às experiências do pensamento do autor, mas unicamente ao sentido do texto em si mesmo" (citado por Dejours, 1999c, p. 212).

O que incomoda Dejours é o fato desses respeitados hermeneutas terem como projeto de objetividade de suas atividades a eliminação de qualquer resquício de subjetividade. Em outras palavras, na sua démarche hermenêutica e científica nas ciências humanas, Ricoeur se esforça em expurgar "os restos relativos à psicologia do sujeito, seus modos de pensamento, seu sofrimento, suas intenções e, de uma maneira mais geral, sua subjetividade" (Dejours, 1999c, p. 212).

Ora, a Psicodinâmica do Trabalho, ao tentar entender a ação de um determinado sujeito em um contexto determinado de trabalho, sabe que todo comportamento é motivado, tem um sentido. Se uma certa conduta é insólita, isso se deve ao sofrimento subjetivo e às estratégias defensivas contra esse sofrimento. A inteligibilidade desse ato do sujeito vem não da conduta que ele expressa, mas do sofrimento que o motiva. A racionalidade que emerge a partir dessa análise do sofrimento é denominada por Dejours de racionalidade páthica. Ela se encontra no centro mesmo da investigação da Psicodinâmica do Trabalho.

Logo, a Psicodinâmica do Trabalho "não é uma disciplina voltada somente para a produção de conhecimento sobre as relações entre sofrimento, prazer e trabalho (...) o sofrimento não é um objeto de pesquisa como os outros. A palavra autêntica, pronunciada sobre o sofrimento, é quase sempre, ao mesmo tempo, demanda de auxílio" (Dejours, 1999c, p. 215). Dejours defende então que "a pesquisa é também uma ação, e a investigação é também uma prática (ou melhor, uma práxis)” (p. 215).

\section{A Psicodinâmica do Trabalho e a Teoria da Ação}

Para dar fundamento teórico e metodológico para essa posição da Psicodinâmica do Trabalho sobre a pesquisa enquanto práxis, o autor vai se apoiar na teoria da ação comunicacional de Habermas (Dejours, 1997).

\footnotetext{
${ }^{11}$ Para uma compreensão mais aprofundada dessas condições, consultar Dejours (1999c, pp. 208-210).
} 
Laudrière e Gruson (1992), ao apresentarem a teoria de Habermas, ressaltam como este avança as teorias da ação desenvolvidas por Aristóteles e Weber, acrescentando a elas a idéia de que há também uma racionalidade subjetiva que norteia a ação. Para Habermas (Dejours, 1997, pp. 67-69) existem três racionalidades para se entender a problemática sociológica da ação e, no nosso caso, a ação no mundo do trabalho: a teleológica, voltada ao mundo objetivo, ao agir cognitivo e instrumental e ao agir estratégico, que, embora leve as pessoas em consideração, as entende como instrumentos; a axiológica, voltada ao mundo social, à legitimidade de uma ação, ao agir moral e ético; e, finalmente, a racionalidade subjetiva, voltada ao mundo pessoal, ligada ao agir dramatúrgico, à autenticidade, à veracidade e à coerência expressiva do indivíduo (Laudrière \& Gruson, 1992; Dejours, 1999c).

A ação, para a Psicodinâmica do Trabalho, é ligada à idéia de que a organização do trabalho muitas vezes não leva em conta ou viola a racionalidade subjetiva. O trabalho é também uma ação, mas dependendo de como está organizado, ele impede o indivíduo de pensar a racionalidade dessa ação, o que gera, ao mesmo tempo, uma limitação na capacidade de se pensar.

Dejours propõe então o exercício da reflexão coletiva, que supõe mais que uma discussão em conjunto, mas uma ação visando a apropriação de uma inteligibilidade comum, regida pela intercompreensão de acordos e normas, produção de novas regras do trabalho e do métier. É necessária, nesse sentido, a criação de um espaço público de deliberação no qual as pessoas possam falar e se escutar para que a transformação da organização do trabalho ocorra. A confrontação de opiniões sobre o trabalho terá então o sentido de desenvolver a capacidade das pessoas pensarem individual e/ou coletivamente.

A organização do trabalho é um compromisso negociado entre quem o organiza e quem o faz. Ela evolui e se transforma: as instalações mudam, o mercado muda, o cliente muda, as relações de trabalho mudam e transformam a qualidade do trabalho. A organização do trabalho é uma relação social, é um compromisso entre objetivos e prescrições (procedimentos, maneira de organizar o trabalho, método) e as dificuldades reais para a realização do trabalho.

A organização do trabalho é freqüentemente pensada por cada um dos níveis hierárquicos a partir da compreensão que os trabalhadores têm do seu próprio trabalho sem que um consiga entender as dificuldades e a racionalidade que rege a prática dos outros. $\mathrm{O}$ agir comunicacional busca por meio da intercompreensão, tornar visíveis as razões, a racionalidade, o sentido do trabalho, a problemática vivida pelos trabalhadores para realizar sua atividade e por que (pelo que) eles buscam respostas para si próprios e para os outros trabalhadores e demais níveis hierárquicos.

Se o trabalhador é capaz de pensar o trabalho, de elaborar essa experiência ao falar, de simbolizar o pensamento e chegar a uma interpretação, ele tem a possibilidade de negociar, de buscar um novo sentido partilhado, de transformar e fazer a organização do trabalho evoluir.

\section{A intervenção e a pesquisa em Psicodinâmica do Trabalho}

Quando falamos em intervenção e pesquisa em Psicodinâmica do Trabalho não estamos nos referindo somente à pratica dos psicodinamistas do trabalho que escolhem essa teoria e método e a aplicam integralmente tal e qual ela é descrita por Dejours (1993a). 
Estamos nos dirigindo àqueles que buscam nesse referencial teórico algum apoio para a sua prática e/ou reflexão teóricas.

A Psicodinâmica do Trabalho se insere no campo da psicologia do trabalho e da tradição compreensiva (Dejours, 1999c). A clínica do trabalho busca desenvolver o campo da saúde mental e trabalho, partindo do trabalho de campo, se deslocando e retornando constantemente a ele, ligando a intervenção à pesquisa pautada nos princípios da pesquisaação. Visa a intervir em situações de trabalho, compreender os processos psíquicos envolvidos e formular avanços teóricos e metodológicos reproduzíveis a outros contextos. Segundo Dejours "a psicodinâmica do trabalho é antes de tudo uma clínica. Ela se desdobra sobre um trabalho de campo radicalmente diferente do lugar da cura. Afirmar que ela se trata de uma clínica implica que a fonte de inspiração é o trabalho de campo e que a toda a teoria é alinhavada a partir deste campo" (Dejours, 1993b, p. 137).

As intervenções devem levar os trabalhadores a um processo ativo de reflexão sobre o próprio trabalho, de modo a permitir sua apropriação e emancipação e a conduzir a uma reconstrução coletiva do trabalho.

É dentro dessa perspectiva que pensamos avançar a constituição de um modelo clínico no campo da saúde mental e trabalho que subsidie a atuação dos profissionais em situações concretas de trabalho e que incorpore os aspectos subjetivos e menos visíveis do trabalho como elementos indissociáveis desse tipo de estudo e atuação. Pensamos também que esses princípios devem nortear as práticas de tratamento de indivíduos acometidos por doenças ligadas ao trabalho e de retorno à atividade de trabalhadores afastados por restrições laborais.

Nessa perspectiva, todas as ações - quer sejam voltadas para a transformação de situações de trabalho, quer para prevenção de doenças ligadas ao trabalho, para tratamento ou reabilitação - ganham um novo olhar a partir da compreensão de que, se o trabalho é gerador de doenças e sofrimento, qualquer ação que vise a sua transformação ou vise a amenizar o sofrimento dos trabalhadores adoecidos ou em risco de adoecimento deve se dar a partir de mudanças na relação das pessoas com o seu trabalho, ou seja, com o ato de trabalhar.

Isso significa considerar a importância do trabalho e sua influência em todos os âmbitos do viver e apontar para a construção de um novo modelo de intervenção na área, voltado para uma abordagem que considere os aspectos subjetivos do trabalho e a sua centralidade enquanto elemento constituidor do indivíduo e da sua identidade.

Uma das descobertas mais importantes realizadas pela teoria dejouriana foi a constatação de que os indivíduos desenvolvem mecanismos de defesa individuais e coletivos para fazer frente ao sofrimento e aos constrangimentos ligados ao trabalho. $\mathrm{O}$ adoecimento de um ou de vários indivíduos fragiliza esses mecanismos e desestabiliza o grupo, pois evidencia o caráter patologizante do trabalho, o que leva os próprios trabalhadores a discriminarem e responsabilizarem o indivíduo que adoeceu como fraco, ou pior, como simulador de adoecimento. Isso ocorre para que possam suportar o medo ante os riscos a que estão expostos.

Esse tipo de mecanismo tem também um aspecto coercitivo que leva os trabalhadores a desenvolverem estratégias coletivas de silêncio - de "não poder fazer nada pelo sofrimento alheio" - e ao individualismo. Para se tocar nessa questão é preciso considerar os processos sociais e psíquicos envolvidos, o preconceito e a discriminação dos sujeitos que já tiveram algum comprometimento físico ou mental e precisaram ser realocados. É necessário compreender o indivíduo enquanto ser social e, ao mesmo tempo, singular, 
portador de características únicas, com uma inteligência particular para realizar seu trabalho e com um jeito e ritmo próprios.

As práticas de tratamento e reabilitação devem proporcionar ao trabalhador não somente a tomada de consciência, mas também uma instrumentalização que permita mudar sua relação com o trabalho, transformando o processo de tratamento em um processo de participação ativa e em uma ação transformadora.

A reintegração dos trabalhadores com restrição laboral passa, ainda, por relações subjetivas, pelas questões da sub ou hiper utilização das capacidades psíquicas, cognitivas e físicas dos trabalhadores nos novos postos de trabalho, por uma mudança de identidade, pelas relações com os demais trabalhadores que deverão assumir tarefas que os "restritos" não podem realizar etc.

Enfim, estamos diante de um campo complexo e inovador. Acreditamos que ainda há muito o que desenvolver, tanto do ponto de vista teórico quanto do metodológico. Considerar a complexidade dos aspectos apontados, tanto em intervenções em postos de trabalho e tratamento de acometidos por adoecimentos ligados ao trabalho, quanto na readaptação ao trabalho dos portadores de restrições laborais, é um novo desafio aos trabalhadores que se interessem por esse campo.

Work and Subjectivity: the psychodinamic of the work view

The present article discusses the theoretical aspects of the relationship between subjectivity and work organization. For such we utilize the basic theoretical support of dejourian theory: psycoanalysis, hermeneutics and theory of action. We seek to subsidize the reader who whishes to utilize the work clinic in their activity of intervention and research to advance theoretically and to get acquainted with the modern debate developed by Psychodynamic of Work.

Keywords: Mental Health and Work, Psychodinamic of Work.

Endereços para contato com os autores: lancman@usp.br ou suchida@fgvsp.br

Manuscrito recebido em: 11/03/2003

Aprovado para publicação em: 13/05/2003

\section{Referências bibliográficas}

Arendt, H. (2000). Eichmann em Jerusalém. Um Relato sobre a banalidade do mal. São Paulo: Cia. das Letras.

Arrighi, G. (2000). O Longo Século XX (3 $3^{\mathrm{a}}$ ed.). Rio de Janeiro: Contraponto. São Paulo: Unesp.

Bergamini, C. W. (1994). Liderança: Administração do Sentido. São Paulo: Atlas.

Bergamini, C. W. (1997). Motivação nas Organizações (4a ed.). São Paulo: Atlas.

Billiard, I. (2001). Santé mentale et travail. l'emergence de la psychopathologie du travail. Paris: La Dispute. 
Boyett, J. \& Boyett, J. (1999). O Guia dos Gurus (4ª ed.). Rio de Janeiro: Campus.

Dejours, C. (1993a). Travail, usure mental. De la psychopatologie du travail à la Psychodynamique du travail (ed. ampliada). Paris: Bayard.

Dejours, C. (1993b). Intelligence pratique et sagesse pratique: deux dimensions méconnues du travail réel, Education Permanente (Comprendre le travail, Première partie), 116, 47-69.

Dejours, C. (1993c). Pour une clinique de la médiation entre psychanalise et politique: la psychodynamique du travail. Revue Trans, 3, 131-156.

Dejours, C. \& Abdoucheli, E. (1994). Desejo ou Motivação? A Interrogação Psicanalítica sobre o Trabalho. In M. I. S. Betiol (Org.), Psicodinâmica do Trabalho (pp. 33-43). São Paulo: Atlas.

Dejours, C. (1997). O fator humano. Rio de Janeiro: Fundação Getúlio Vargas.

Dejours, C. (1999a). A Banalização da injustiça social. Rio de Janeiro: Fundação Getulio Vargas.

Dejours, C. (1999b). Conferências brasileiras. São Paulo: Fundap e Eaesp-FGV.

Dejours, C. (1999c). Psychologie clinique du travail et tradition compréhensive, In Y. Clot (Org.), Les Histoires de la Psychologie du Travail. Approche pluri-disciplinaire (pp. 195-219). Toulouse: OctaresÉditions.

Festinger, L. (1975). Teoria da dissonância cognitiva. Rio de Janeiro: Zahar.

Freitas, M. E. (2000). Cultura Organizacional: Identidade, Sedução e Carisma? (2 ${ }^{\mathrm{a}}$ ed.). Rio de Janeiro: Fundação Getúlio Vargas.

Harvey, D. (2000). A condição pós-moderna (9ª ed.). São Paulo: Loyola.

Kets de Vrie, M. F. R. (1997). Liderança na empresa. São Paulo: Atlas.

Laplanche, J. \& Pontalis, J. B. (1976). Vocabulário de Psicanálise (3 ${ }^{\mathrm{a}}$ ed.). Lisboa: Moraes.

Laudrière, P. \& Gruson, C. (1992). Étique et gouvernabilité. Paris: PUF.

Maslow, A. H. (1954). Motivation and personality. New York: Harper e Row.

Motta, F. C. P. \& Caldas, M. P. (1997). Cultura organizacional e cultura brasileira. São Paulo: Atlas.

Possas, M. L. (1988). O projeto teórico da "escola da regulação". Novos Estudos Cebrap, 21, 195-212.

Rouanet, S. P. (1978). Imaginário e dominação. Rio de Janeiro: Tempo Brasileiro.

Sennett, R. (1999). A corrosão do caráter. Rio de Janeiro: Record.

Taylor, F. W. (1995). Princípios de Administração Científica. São Paulo: Atlas.

Wagner III, J. A. \& Hollenbeck, J. R. (1999). Comportamento Organizacional: Criando Vantagem Competitiva. São Paulo: Saraiva.

Womack, J. P., Jones, D. T. \& Roos, D. (1992). A Máquina que mudou o Mundo. Rio de Janeiro: Campus. 